\title{
Caso de quiste óseo benigno aneurismal en un canino
}

\author{
Karen Vega-Benavides ${ }^{1} \bowtie$, Roberto Leiva-González², María Soto², Santiago Ramírez-Jiménez ${ }^{2}$, \\ María Pacheco-Rojas ${ }^{2}$
}

1. Académica, Hospital Especies Menores y Silvestres, Escuela Medicina Veterinaria, Universidad Nacional. Email: karenluvega@hotmail.com

2. Estudiantes de Internado, Rotación de Menores, Escuela Medicina Veterinaria, Universidad Nacional. Email: l.santiagorj@gmail.com, maripacheco25@gmail.com, marisj@msn.com, jorgerojas@gmail.com, rolego 99@hotmail.com

El quiste óseo aneurismático es una lesión benigna que puede originarse en la metáfisis de huesos largos, pelvis y columna vertebral; puede provocar abombamiento del hueso (lo que permite que sea visible), y ocasionar dolor de intensidad variable. A pesar de ser poco común, en caninos, es principalmente reportado en razas grandes. Dentro de las posibilidades etiopatogénicas se encuentran la malformación venosa, trauma o neoplasia (por incremento de presión venosa). A menudo es necesario el tratamiento quirúrgico, que procura ser poco invasivo, al ser de carácter benigno, sin embargo; es la recaída local la complicación más común. Paciente, canino, bóxer, de seis años de edad. Presenta dolor y distención abdominal, pérdida de apetito y vómito. Se realiza hematología, con perfil químico completo, obteniendo resultados normales. Ecográficamente se evidencia fluido libre, abundante, en cavidad abdominal, además de una cavidad circunscrita con contenido también hipo ecoico, pero con mayor turbidez. Ambos fluidos son analizados, se reporta únicamente trasudados. Se determina la importancia de realizar laparotomía exploratoria, como apoyo diagnóstico y terapéutico; sin embardo, debido a la cantidad de efusión abdominal se decide iniciar una terapia diurética previa, para mejorar el pronóstico quirúrgico, al reducir el riesgo de descompensación por cambio de presión en vasos sanguíneos, al descomprimir y extraer el fluido. Después de 5 días con manejo antiinflamatorio y diurético, el animal reduce considerablemente la efusión abdominal, lo cual hace más evidente el tamaño de la cavidad quística y el efecto marcado que a pesar de no estar adherido a órganos, generaba un desplazamiento en ellos, por su gran tamaño, en ese momento se realiza el procedimiento quirúrgico. En la exploración abdominal, se evidencia una estructura cavitaria, de pared delgada pero consistente, turgente con contenido líquido en el interior y presencia de material fibrocartilaginoso; además, se determina que está adherido al hueso de la pelvis; el quiste es resecado totalmente, y se raspa el borde óseo pegado al quiste. El material es enviado a estudio histopatológico, y se obtiene el diagnostico de quiste óseo benigno aneurismal. El manejo posquirúrgico se realizó con antiinflamatorio, analgésico y antibiótico. El animal respondió de manera satisfactoria, no presentaba dolor (escala Glasgow); la evaluación radiográfica posquirúrgica no presentó alteración ósea, y las ecografías de control posquirúrgicas sin hallazgos relevantes. La calidad de vida del animal mejoró, y fue dado de alta. La semiología en el abordaje de nuestros pacientes puede brindar mucha orientación en el abordaje del caso, pero a su vez, puede ser muy confusa e inespecífica, por lo que el apoyo en pruebas complementarias es de gran relevancia, y representa una diferencia importante en el abordaje, y por ende en la resolución positiva de nuestros casos clínicos. La imagenología, procedimientos quirúrgicos y estudios histopatológicos, nos permiten además de brindar diagnósticos definitivos, trabajar con pronósticos más objetivos.

\ Autor para correspondencia Karen Vega-Benavides: karenluvega@hotmail.com 